\title{
A STUDY ON EFFECT OF LINE WIDTH, COMPOSITION AND FIRING TEMPERATURE ON THE MICROSTRIPLINE PROPERTIES
}

\author{
SUNIT RANE* and VIJAYA PURI \\ Thick and Thin Film Device Lab, Department of Physics, Shivaji University, \\ Kolhapur-416004 (India)
}

(Received 8 June 2000; In final form 12 July 2000)

\begin{abstract}
The transmittance and reflectance of microstriplines of different widths, fabricated by thick film and thin film technology are studied in the $\mathrm{X}$ and $\mathrm{Ku}$ band $(8-18 \mathrm{GHz})$. The fritless thick film $\mathrm{Ag}$ pastes with different binder composition was formulated indigenously and screen-printed the microstriplines on alumina substrate. These microstriplines were compared with the microstriplines made from ESL (USA) pastes and also $\mathrm{Cu}$ thin film circuits. The effect of line width, composition and firing temperature on the thick film microstriplines was investigated. The transmittance of all the indigenously prepared Ag thick film paste compared well with microstriplines prepared with ESL pastes. All these thick film pastes gave good transmittance upto $18.0 \mathrm{GHz}$. The results indicate firing at $700^{\circ} \mathrm{C}$ gives best films, and also $18 \mathrm{mil}$ or 20 -mil line width is more suitable than conventional 25 -mil line width if thick films are used for metallization upto $18.0 \mathrm{GHz}$.
\end{abstract}

Keywords: Fritless thick film paste; Microstriplines; Transmittance

\section{INTRODUCTION}

Due to the tremendous growth in the IT sector, the demand for high frequency microstripline components have increased. There is a dearth of materials useful for such purposes. Also there is a need for

*Present address: Centre for Materials for Electronics Technology (C-MET), Panchawati, Dr. Homi Bhaba Road, Pune-411008 (India). Tel.: 91-020-339373, Fax: 91-020-343085, e-mail: sunit@cmetp.ernet.in 
indigenous fabrication of microstripline components which can be used for high microwave frequencies upto $18.0 \mathrm{GHz}$. Simple microstriplines of different widths are needed for a variety applications and to the authors knowledge the high frequency i.e., beyond $12.0 \mathrm{GHz}$, characterization of the microstriplines have not been studied by many workers. Until recent years, thin film [1,2] was the only process used for metallization for microwave purposes. Some recent studies by us [3-6] and others [7-9] have shown that thick films can also be used as conductor part of the circuits.

This paper reports the transmittance and reflectance of the microstriplines of different widths from $16-\mathrm{mil}$ to $27-\mathrm{mil}$ in the $8-18 \mathrm{GHz}$ frequency range. The lab prepared (SBR series) $\mathrm{Ag}$ thick film pastes have been compared with ESL (USA) paste and also $\mathrm{Cu}$ thin film metallisation. The effect of firing temperature $700^{\circ} \mathrm{C}-900^{\circ} \mathrm{C}$ on the microwave transmittance and reflectance of the microstripline samples are also reported in this paper.

\section{EXPERIMENTAL}

The thin film microstriplines of different width 16-mil $(406 \mu \mathrm{m})$ to 27-mil $(686 \mu \mathrm{m})$ were photolithographically fabricated on the $\mathrm{Cr}-\mathrm{Cu}$ (vacuum evaporation + electroplating) metallized alumina (99\% Kyocera) substrate. Similarly, thick film microstriplines of SBR3, SBR4, SBR5, SBR6 and ESL (USA) pastes deposited using screen printing technique on alumina $(96 \%$ Kyocera) substrate. The length of all the microstriplines were $2.54 \mathrm{~cm}$. The lab prepared SBR series (SBR3, SBR5) and (SBR4, SBR6) paste having the composition of Metal: Inorganic: Organic of $80: 10: 10$ and $83: 7: 10$ by weight percent respectively. In all these, the metal was $\mathrm{Ag}$ powder and inorganic was $\mathrm{PbO}, \mathrm{Al}_{2} \mathrm{O}_{3}, \mathrm{TiO}_{2}, \mathrm{Bi}_{2} \mathrm{O}_{3}$ in SBR3 and SBR4 and only $\mathrm{Bi}_{2} \mathrm{O}_{3}$ in SBR5 and SBR6. The thickness of $\mathrm{Cu}$ thin film microstripline was $\sim 5 \mu \mathrm{m}$ and that of thick film was $\sim 10 \mu \mathrm{m}$. A 250 -mesh screen was used for screen-printing. The screen-printed samples were fired for three different peak firing temperatures (viz. $700^{\circ} \mathrm{C}, 800^{\circ} \mathrm{C}$ and $900^{\circ} \mathrm{C}$ ) in a three zone furnace. The firing schedule of 45 minutes was maintained for all the thick film samples. The microwave 
transmittance and reflectance measurements of both the thin and thick film microstriplines were taken point by point in the $8-18 \mathrm{GHz}$ frequency range with the help of microwave bench consisting of source, isolator, attenuator, directional coupler and detector. Both the thin film and thick film, 3-4 samples were used for each width. The transmittance and reflectance are an average of these samples.

\section{RESULTS}

\section{Thin Film Microstriplines}

The transmittance and reflectance for the $\mathrm{Cu}$ thin film microstriplines as a function of frequency is shown in Figure 1. From the figure, it is seen that the transmittance of microstriplines of width 16 mil and 25 mil show more uniform behavior than the other microstriplines. The average transmittance of $16-\mathrm{mil}$ line is 0.68 and of $25 \mathrm{mil}$ is 0.70 .

For the 18-mil line width, the transmittance shows decreasing tendency at the frequency range 9.0 to $11.4 \mathrm{GHz}$ and increases after

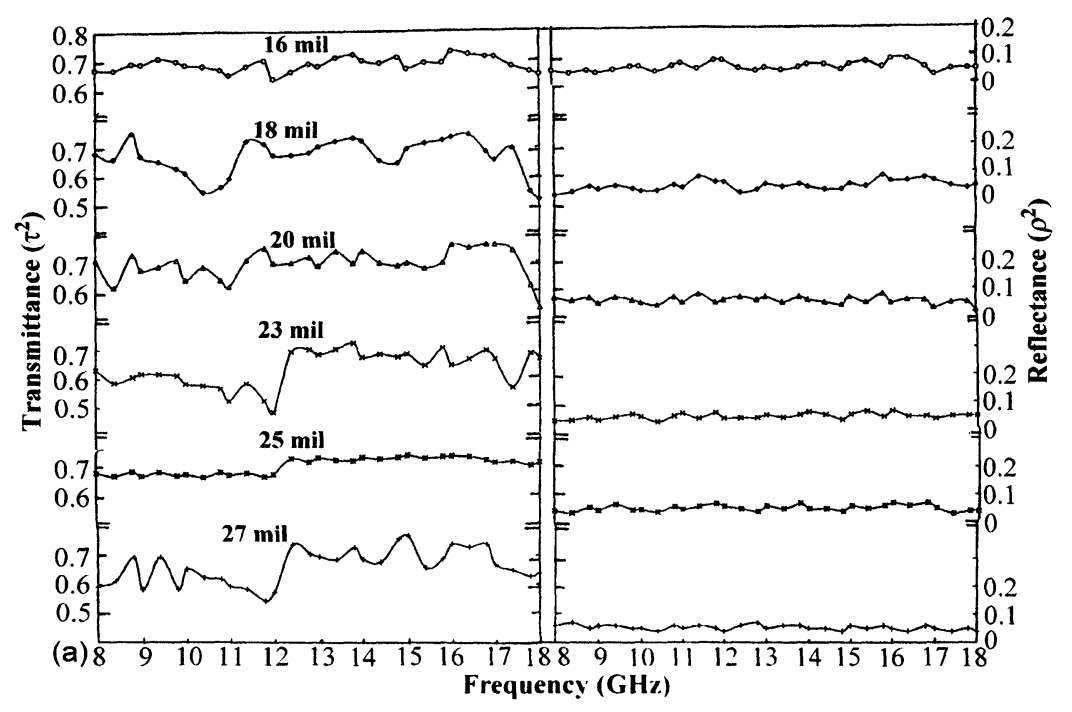

FIGURE 1 Transmittance and reflectance characteristics as a function of frequency for thin film $(\mathrm{Cu})$ microstriplines of different line width. 
11.4 GHz. The decreasing behavior of transmittance is again observed beyond the frequency $17.4 \mathrm{GHz}$. The average transmittance is $\sim 0.65$.

For 23-mil, 25-mil and 27-mil line widths, the transmittance is less between 8 to $12 \mathrm{GHz}$ compared to 12 to $18 \mathrm{GHz}$ frequency ranges. The difference in transmittance at the two-frequency band is high for 23-mil and 27-mil line width. The 23-mil and 27-mil line shows $\sim 0.60$ transmittance for $\mathrm{X}$-band and $\sim 0.75$ for $\mathrm{Ku}$-band. In addition, it is observed that for 25-mil width microstripline, the dispersion is very low for all the frequency range studied. The reflectance data shows a

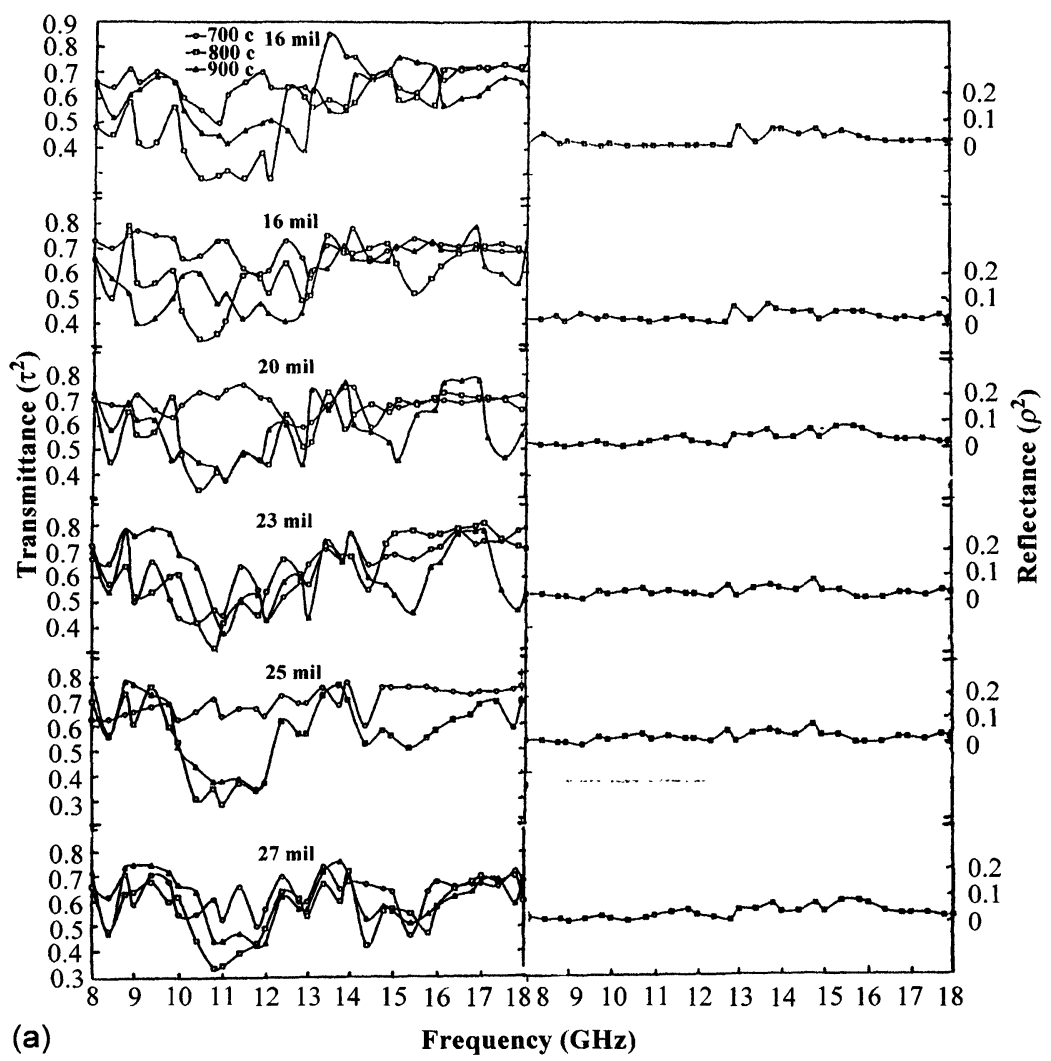

FIGURE 2 Microwave transmittance and reflectance of thick film microstriplines of different width and firing temperatures: (a) SBR3 paste, (b) SBR4 paste, (c) SBR5 paste, (d) SBR6 paste and (e) ESL paste. 


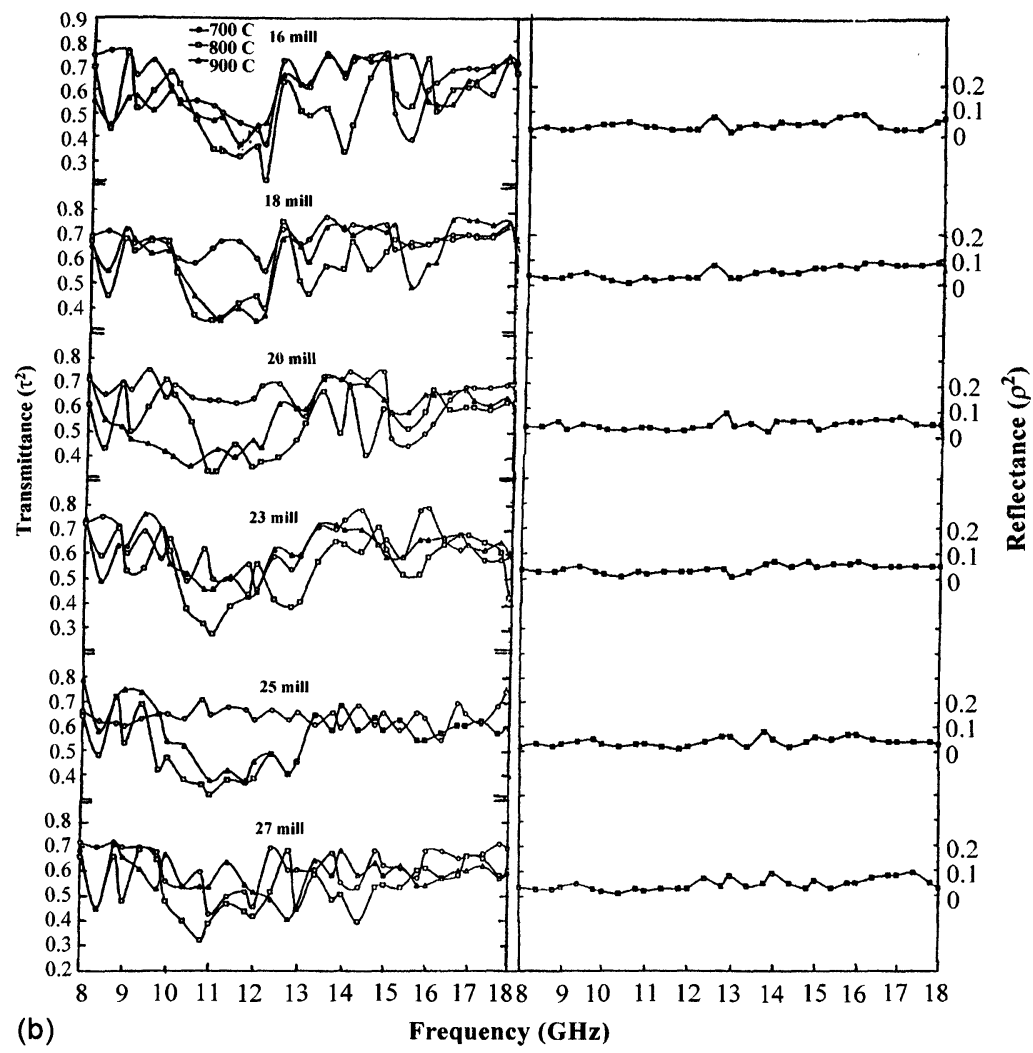

FIGURE 2 (Continued).

width independent dispersive behavior of the microstripline with a reflectance $\sim 0.05$ throughout all the frequency range studied.

\section{Thick Film Microstriplines}

The graphs of transmittance and reflectance of the microstripline of different width fabricated using five different $\mathrm{Ag}$ thick film pastes are given in Figures $2(\mathrm{a}-\mathrm{e})$. The effect of firing temperature is also plotted in these graphs.

From the figures, it is seen that for all the thick film paste compositions including ESL paste, the microstriplines of widths 18-mil, 20-mil and 25 -mil fired at $700^{\circ} \mathrm{C}$ show lesser dispersion as 


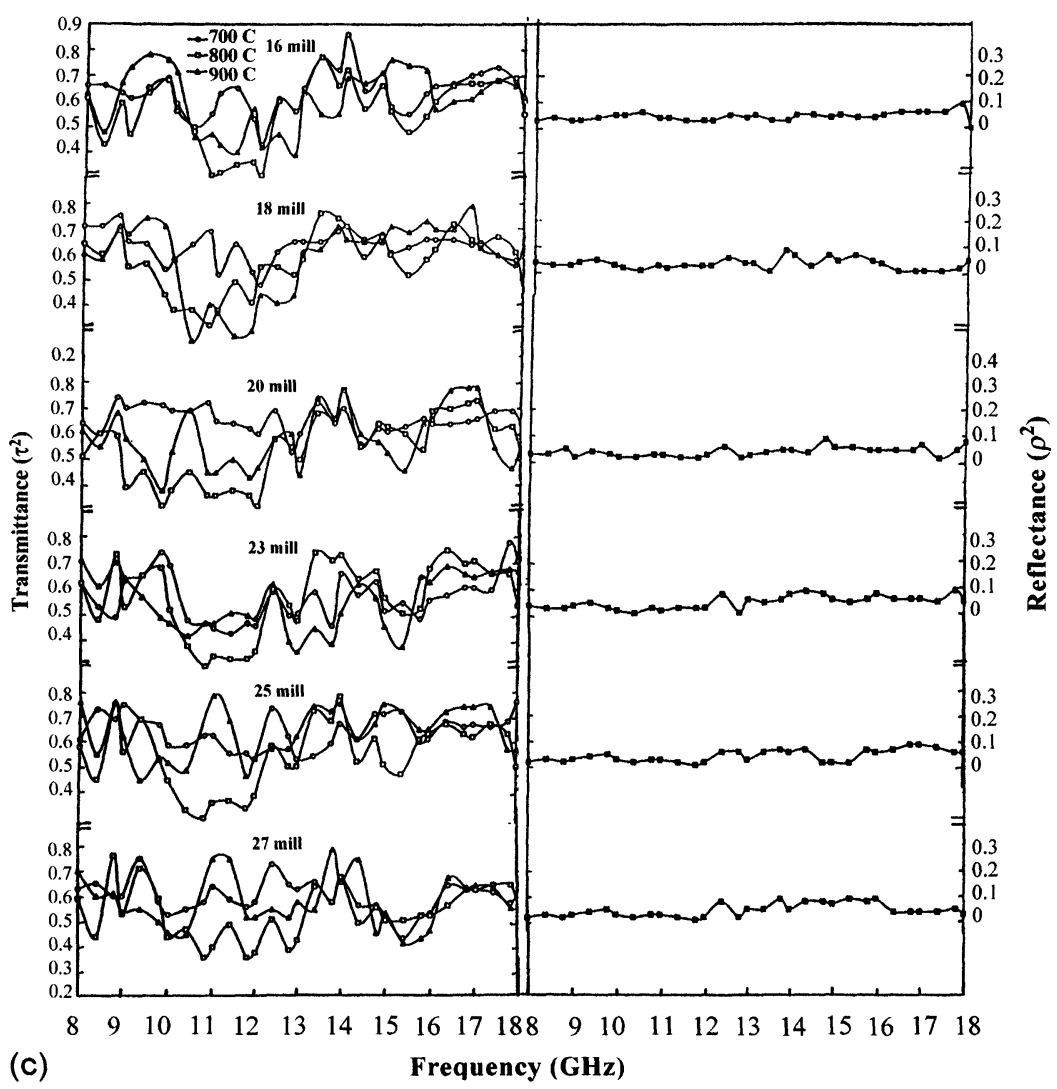

FIGURE 2 (Continued).

compared to other widths and firing temperatures. In all the cases the maximum frequency dependent variation is observed for circuits fired at $800^{\circ} \mathrm{C}$. The microstriplines prepared from SBR3, SBR4 and ESL pastes; 18-mil and 25-mil line width seems to be showing very good transmittance characteristics. Whereas for the microstriplines prepared from SBR5 and SBR6 pastes 20-mil line seems to be better than the other widths. The reflectance data shows composition and firing temperature independent nature for all the frequencies from 8 $18 \mathrm{GHz}$. The average reflectance varying from 0.02 to 0.05 . Compared to the thin film microstriplines, all the thick film microstriplines show large randomness in the variation of transmittance with frequency. 


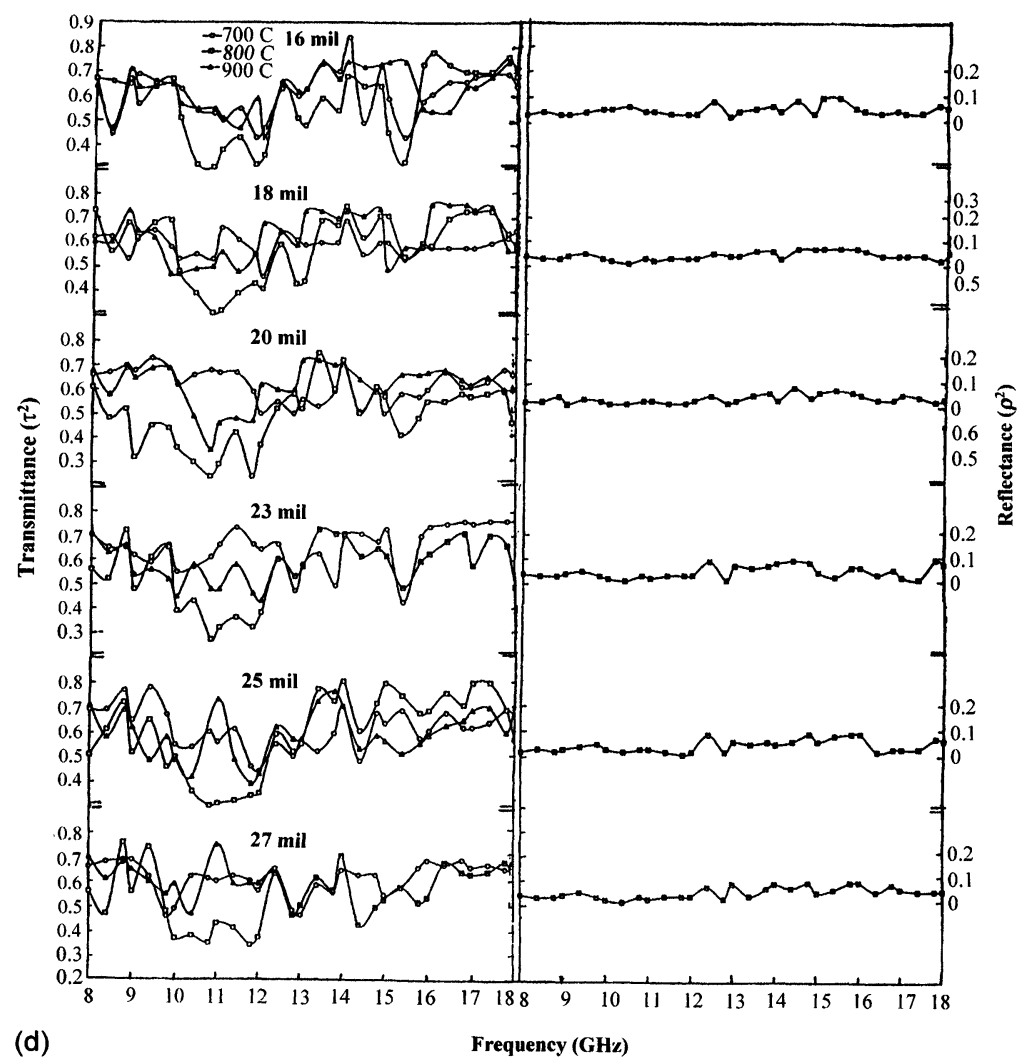

FIGURE 2 (Continued).

The transmission loss data [6] indicate the higher loss for films fired at $800^{\circ} \mathrm{C}$. It is also seen that above $14 \mathrm{GHz}, 20$-mil line is better when thick film is used as metallization and 25-mil is best for all frequencies when both thin film and thick film used for metallisation.

\section{DISCUSSION}

The thick film microstriplines are fabricated on $96 \%$ alumina (Kyocera). The thick film has a natural tendency to planarise the relatively rough surface of the $96 \%$ alumina substrate so that the 


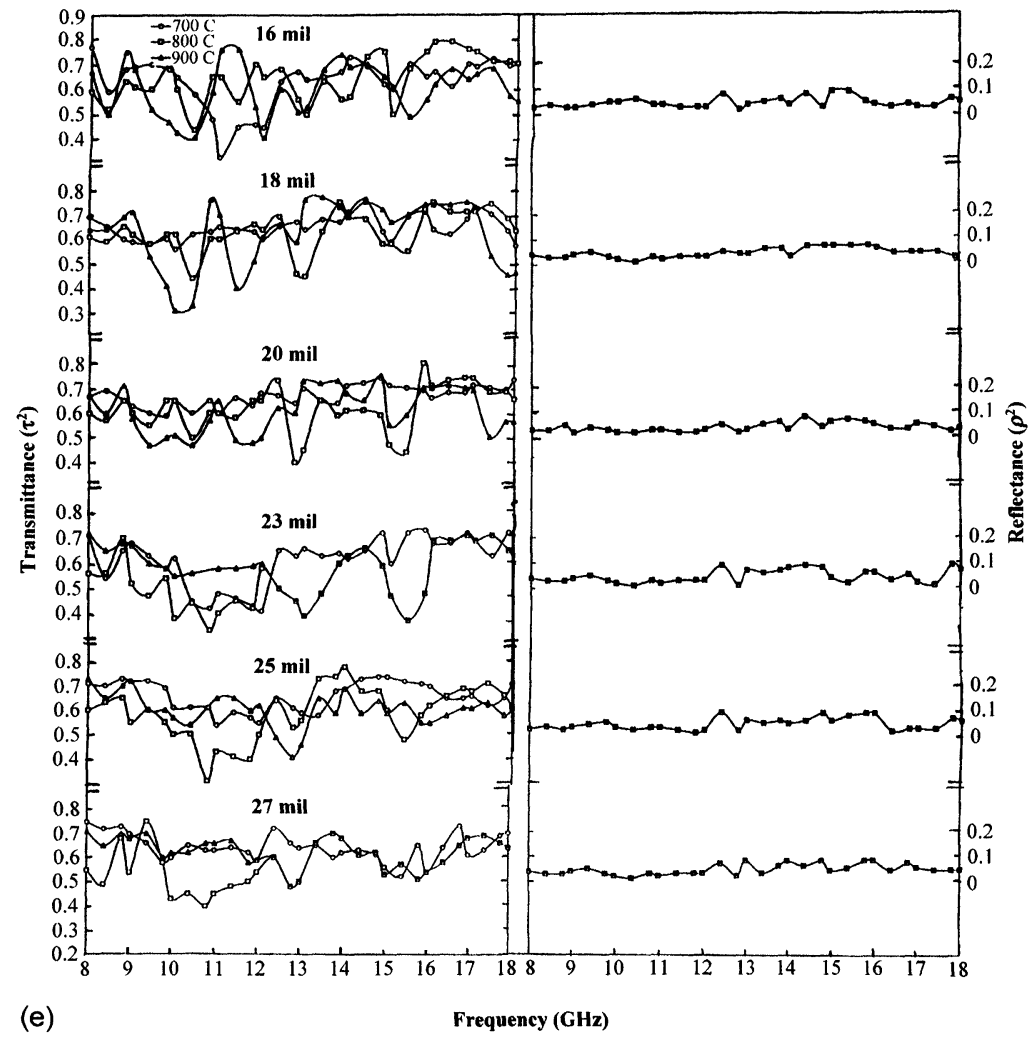

FIGURE 2 (Continued).

surface finish may not play a major role in the circuit performance. More than surface roughness, the rough and porous surface morphology of the thick film circuits is expected to attribute more to the losses in the thick film circuits. The ragged edges and hemispherical shape of thick film fired conductors also contribute to the loss [9]. Our results indicate that in the $8-18 \mathrm{GHz}$ frequency range, both the thin film and thick film microstripline circuit behave almost in a similar way indicating that the specific problems inherent with thick film technology will not be a major problem in this region of microwave frequencies. The cause of losses in the microstripline is similar to both thin and thick film circuits, the effects being enhanced in the thick film circuits. 
Our results show lower transmission loss at higher frequencies $(>15 \mathrm{GHz}$ ). As the frequency increases the current density is higher in the area close to the bottom of the conductor. Both in thin film and thick film microstriplines due to the adhesion process a layer is present at the bottom of the conductor. The layer in the thin film circuit is chromium and the resistivity of chromium is higher than copper. The transmission loss due the $\mathrm{Cr}$ layer is reported [10] to be very much higher than the inorganic dielectric layer present in thick film circuits. This might be the reason why the thin film circuit is also lossy.

The dispersion patterns randomness in frequency does not get steadily worse for high frequencies, on the contrary in most of the cases the randomness is decreased and also transmittance increased. The distortion of signals as they propagate along the surface of the microstripline may not be due only to dispersion in the ordinary sense that the permittivities of the air or the substrate are frequency dependent. It may be due to the fact that each signal separates into two parts, the one travelling in air and the other in the dielectric with different phase velocity [11]. Each of these waves suffers dispersion depending on the extent of frequency dependent permittivity. Another cause of dispersion might be due to coupling of a fundamental TEM mode to $\mathrm{TM}_{0}$ and $\mathrm{TE}_{1}$ surface wave modes. The change in the width of the line changes the characteristic impedance of the lines [12 - 14]. The strip width affects the frequency at which the onset of leaky dominant mode $[15,16]$ occurs and therefore the frequency range over which the proper microstripline mode and the new leaky mode are present simultaneously changes with the line width of the line.

The launcher which is in contact with the microstripline at the input/ output ends are basically co-axial center pin which is in the form of wedge of width $\sim 25 \mathrm{mil}$. The launcher tab since it lies on top of the conductor increases its thickness and consequently reduces its characteristic impedance [17]. This also contributes to the distortions in the microstrip characteristics. These types of discontinuities in the line might produce associated frequency dependent standing wave current [18] existing along the line. The resilient contact launchers were found to give a 0.5 to $0.6-\mathrm{dB}$ loss in $\mathrm{X}$ band and $0.8 \mathrm{~dB}$ in $\mathrm{Ku}$ band. The differences in the reflection coefficients are also so small that one can conclude that irrespective of metallisation process and width of the microstrip all of them are almost matched. 
All the thick film formulations made by us contain $\mathrm{Bi}_{2} \mathrm{O}_{3}$ along with $\mathrm{PbO}, \mathrm{Al}_{2} \mathrm{O}_{3}$ and $\mathrm{TiO}_{2}$ in SBR3 and SBR4 and only $\mathrm{Bi}_{2} \mathrm{O}_{3}$ in SBR5 and SBR6. The fact that the transmittance, reflectance and loss characteristics of all the five formulations are similar indicates that binder composition does not affect the microwave properties.

\section{CONCLUSION}

Our results have proved that combination with suitable binders; silver can be a viable cost effective alternative for microstripline circuits upto $18 \mathrm{GHz}$ frequency. Also our Ag thick film paste compare well with ESL (USA) paste and also $\mathrm{Cu}$ thin film. It is felt that the slightly higher transmission loss associated with thick film technology will not be a problem for most microwave applications. Since the fritless $\mathrm{Ag}$ thick film fired at $700^{\circ} \mathrm{C}$ show comparable properties and in some cases better properties than those fired at $800^{\circ} \mathrm{C}$ and $900^{\circ} \mathrm{C}$, it is felt that a substantial advantage in energy savings and increased furnace life is inherent in firing temperature below the typical $900^{\circ} \mathrm{C}$. Silver paste does not require inert atmosphere for firing; these pastes make attractive alternative for metallisation.

For $\mathrm{Cu}$ thin film microstripline, 25-mil line is the best and average transmittance is high compared with the other widths. The losses in the $\mathrm{X}$ band and $\mathrm{Ku}$ band are almost same. The microstriplines of width 18-mil or 20-mil may be more suitable than the conventional 25-mil line width if thick films are used for metallisation upto $18 \mathrm{GHz}$. The reflectance is independent on firing temperature, width or composition of $\mathrm{Ag}$ paste.

It is felt that when one has to use microstriplines for higher frequencies, the width of the line should be properly designed.

\section{Acknowledgements}

The authors Sunit Rane gratefully acknowledges Department of Science and Technology, India for providing financial assistance for the work and Vijaya Puri acknowledges gratefully University Grants Commission, India for the award of 'Research Scientist B'. 


\section{References}

[1] Sobol, H., IEEE Trans. Parts, Hybrid Packag. (USA), p. 59, June, 1972.

[2] Eda, K. and Miwa, T., IEEE Trans. Microwave Theory and Tech., MTT-38(12), December, 1990.

[3] Puri, V., Hybrid Circuits (UK), 34(28), 28, May, 1994.

[4] Rane, S. B. and Vijaya Puri, Proc. Emerging Microelectronics and Interconnection Tech., p. 395, February, 1998.

[5] Sunit Rane and Vijaya Puri, IETE Technical Review, 16(1), 129, JanuaryFebruary, 1999.

[6] Sunit B. Rane (1999). Ph.D. Thesis, Shivaji University, Kolhapur, India.

[7] Mandhare, M. M., Gangal, S. A., Setty, M. S. and Karekar, R. N. (1988). Active and Passive Ele. Comp., 13, 45.

[8] Nishiki, S. and Yuki, S., IEEE Trans. Microwave Theory and Tech., MTT-30(7), 1104, July, 1982.

[9] Barnwell, P., Wood, J. and Reynolds, Q., Proc. Emerging Microelectronics and Interconnection Tech., p. 399, February, 1998.

[10] Lo, H. L., Kauffman, J. F. and Franzon, P. D., IEEE Trans. Advanced Packaging, 22(1), 16, February, 1999.

[11] King, R. W., IEEE Trans. Microwave Theory and Tech., MTT-36(6), 1080, June, 1988.

[12] Getsinger, W. J. (1979). IEEE Trans. Microwave Theory and Tech., MTT-27, 293.

[13] Itashimoto (1985). IEEE Trans. Microwave Theory and Tech., MTT-33, 624.

[14] Owns, R. P. (1976). Electron Lett., 12, 269.

[15] Oliner, A. A., Radio Science, 22, 907, November, 1987.

[16] Michalski, K. A. and Zheng, D., IEEE Trans. Microwave Theory and Tech., MTT-37(12), 2005, December, 1989.

[17] Chapman, A. G. and Aitchison, C. S., IEEE Trans. Microwave Theory and Tech., MTT-28(2), 130, February, 1980.

[18] Vanhoenade, D. and Hgynen, I., IEEE Microw. Guided and Wave Lett., 5(8), 255, August, 1995. 

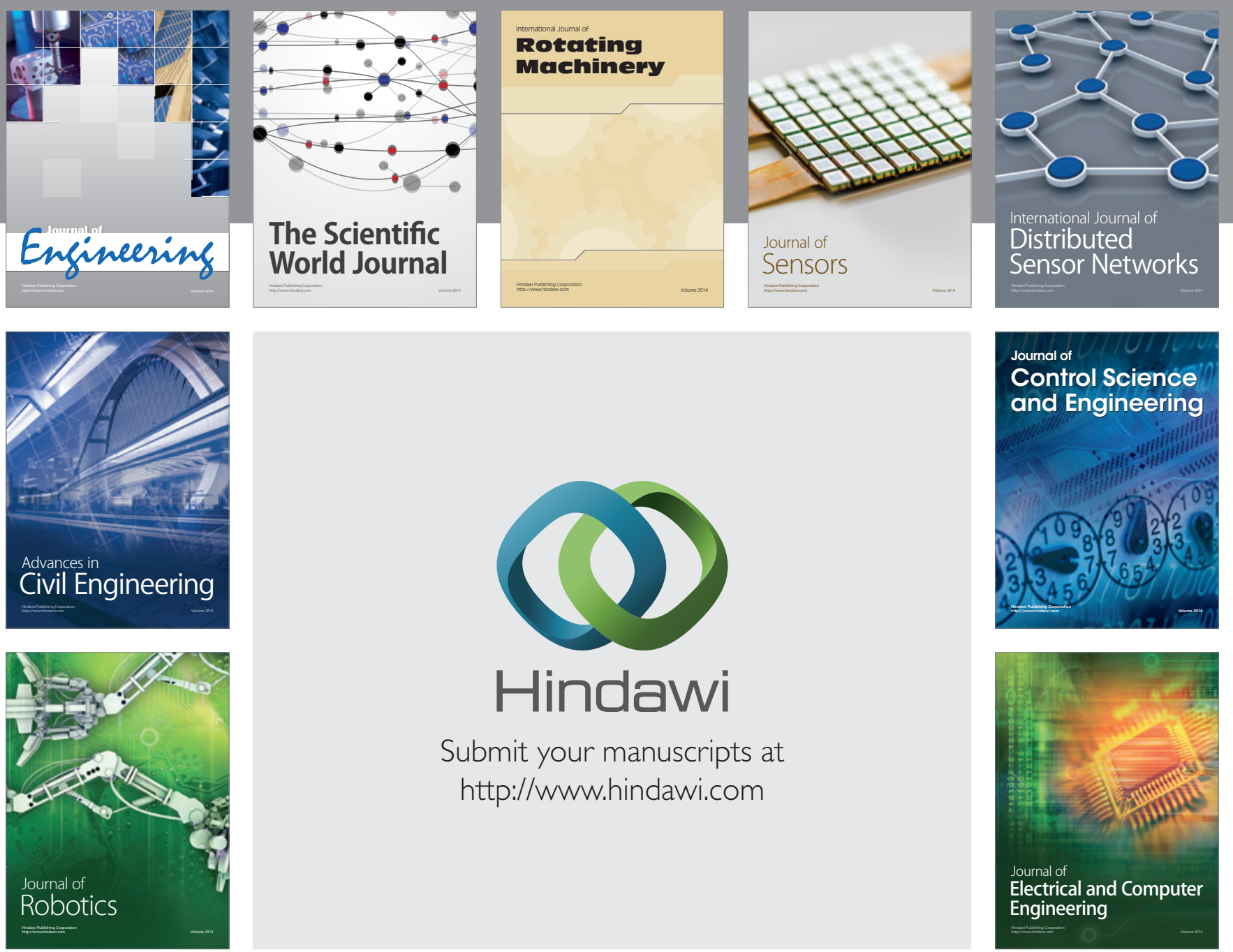

Submit your manuscripts at

http://www.hindawi.com
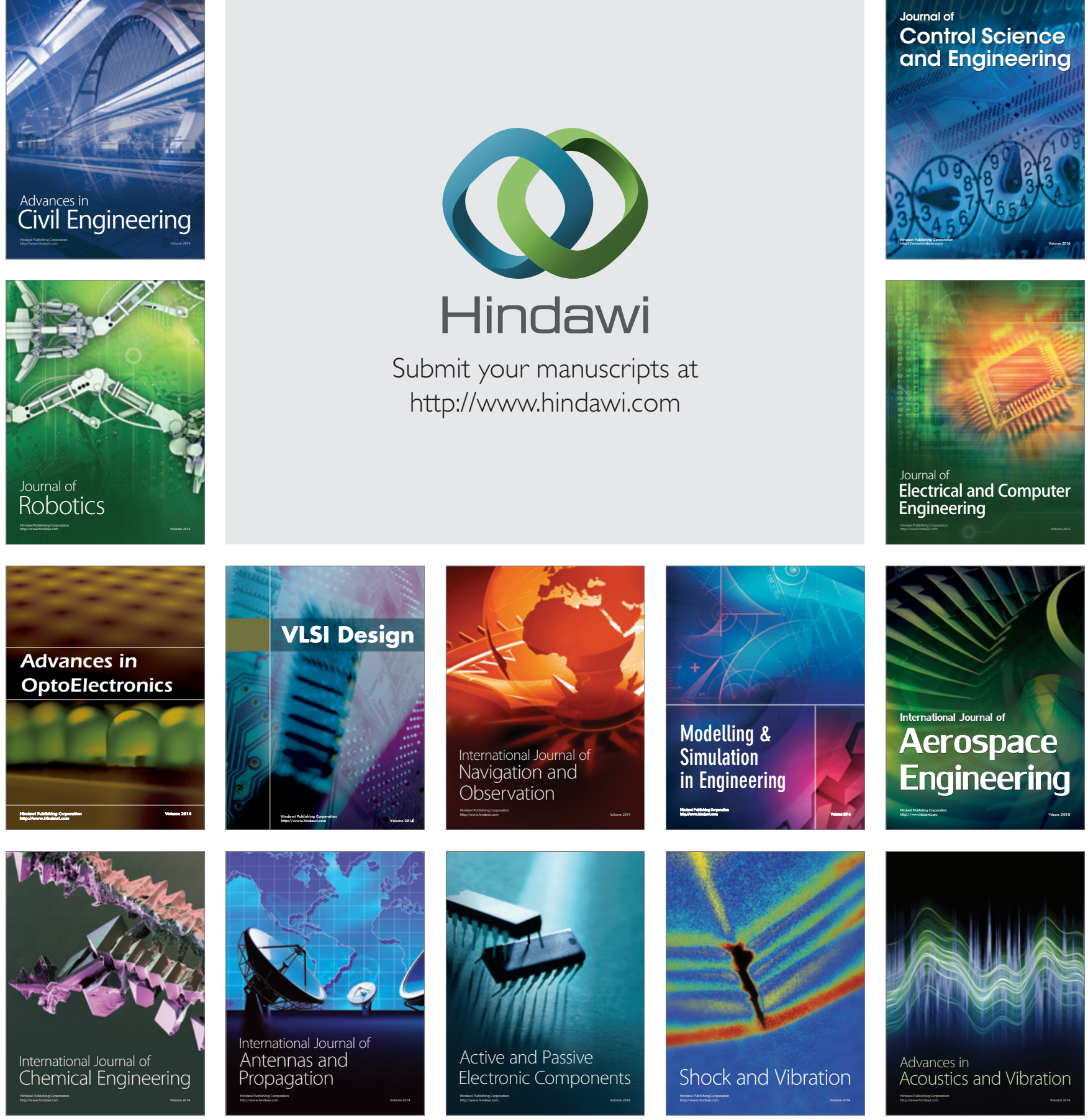